\title{
The Exploration of Entrepreneurship Education for College Students in Entrepreneurship Practice
}

\author{
Zeping Tong \\ School of management \\ Wuhan university of science and technology \\ Wuhan,China \\ Tongzp76@126.com
}

\author{
Tian $\mathrm{Hu}$ \\ School of management \\ Wuhan university of science and technology \\ Wuhan, China \\ 1789882321@qq.com
}

\author{
Guangjun $\mathrm{Ou}$ \\ School of management \\ Wuhan university of science and technology \\ Wuhan,China \\ guangjunou@tom.com
}

\begin{abstract}
Under the big background of "public entrepreneurship, people's innovation", entrepreneurship education in colleges and universities has been paid more and more attention. However, due to the lack of experience accumulation, the entrepreneurship education resources in colleges and universities haven't met the demands of college students' innovation and Entrepreneurship. To solve this problem, this paper proposes "Bi-directional" entrepreneurship education model, which aims to meet the needs of students' innovation and entrepreneurship education through the integration of school resources and social resources, and avoid the shortage caused by the inefficient use of educational resources. In addition, in order to maintain the sustainable development of entrepreneurship education, this paper promotes the improvement of "Bi-directional" entrepreneurship education model, along with bringing into broader ecological environment of entrepreneurship, and finally puts forward some suggestions. Both the model and the suggestions have good feasibility.
\end{abstract}

Keywords-Entrepreneurship Education; Maker Space ; Maker

\section{PROBLEMS}

Entrepreneurship education originated in the United States in the 20th Century, and has gained great success and far-reaching impact. At the end of the last century, Tsinghua University learned from the American model and introduced it into the campus entrepreneurship competition, and later developed into the national "Challenge Cup" entrepreneurship competition. Since then, entrepreneurship education in China has been enlightened. In the 21st Century, China gradually began to attach importance to the entrepreneurship education. With the Ministry of Education constantly issuing related documents and setting up a committee of entrepreneurship education, entrepreneurship education officially walked into the colleges and universities. Some colleges and universities began to set up entrepreneurship Colleges, but there is no independent entity, basically one staff with two functions. Nevertheless, its significance is obvious and entrepreneurship education has become an important part of college education.

As a result of the late start and insufficient attention in the early stage, many problems still exists in the theory and practice of entrepreneurship education in colleges and universities. First, entrepreneurship education has not been integrated into the university education system, with the problems in reality: there are limited entrepreneurship education resources, the concept of entrepreneurship education lags behind, the curriculum system is not perfect, and qualified teachers are not sufficient. Second, there is a lack of effective coordination in the practice of entrepreneurship education. Although government has policies on it and schools have corresponding documents, when students want to start their own business, it is more common that students do not know who they should look for and how to handle with it. Instead, students can only rely on themselves to explore. Students lack adequate training, guidance and counseling and are subject to suffer from entrepreneurial setbacks, which will reduce the overall entrepreneurial quality and quantity discount so that it is difficult to form a good atmosphere of entrepreneurship culture.

\section{The MaIn Problems Faced By EnTREPRENEURShiP EdUCATION}

\section{A. Teachers}

After the slogan " public entrepreneurship, people's innovation " was introduced, college students are the main power in innovation and entrepreneurship. However, colleges and universities couldn't be able to provide adequate career guidance teachers. The main sources come from the professional teachers in related colleges, such as the school of management, school of business or school of economics and management. Besides so, these professional teachers cannot provide enough knowledge and skills due to

This research was supported by the Humanities and Social Sciences Research Project of Hubei Province Department of Education (No. 16Z027) and the Teaching and research reform project of Wuhan University of Science and Technology (No. 2014z030). 
their major limitation or research interest limitation.

Also, in entrepreneurship mobilization of resources, these professional teachers are subject to long-term work at school, and could not help students who want business startups to obtain corresponding resources. Under this situation, the entrepreneurship education, to a certain extent, is limited to theory study and case study, and cannot effectively help students start their business to entrepreneurship practice, or provide general and substantive help in the practice of entrepreneurship.

\section{B. Students}

Students are the main power of innovation and entrepreneurship, but not all of the students have entrepreneurial needs. On one hand, some students cannot understand the universality of entrepreneurial classes, not willing to take the appropriate courses; on the other hand, some students who have the needs of business startups lack sufficient guidance. There is also another need: to participate in various entrepreneurial competitions. The motivation of participating in entrepreneurial contests can be divided into: (1) to obtain various bonus items, such as scholarships, postgraduate qualification exam waiver, which usually goes to the "Challenge Cup" entrepreneurship contest winner; (2) to practice their own entrepreneurial skills and cultivate entrepreneurship; (3) to obtain entrepreneurship rewards, including the local entrepreneurship awards; (4) All of above. Where the students will move towards entrepreneurship practice, there should provide various entrepreneurial resources.

But the difficulty for the students lies in a fact that they don't know how to choose. In order to obtain the awards, schools will also organize some excellent students competitions. This will eventually result in inefficient allocation of resources.

\section{Curriculum}

Currently, from the government's point of view, entrepreneurship promotion is proposed as a national strategy and the relevant departments of the government are all involved. Among them, the Ministry of Education and the State Department of Education are the most direct participants. They promote the establishment of entrepreneurship colleges in colleges and universities, or offer entrepreneurial courses, which are the guidelines. How to effectively launch courses involves the modification of training programs, including training objectives, knowledge and skills to be mastered, and so on. It is obvious that, presently few schools are able to establish a relatively systematic curriculum system to promote entrepreneurship and entrepreneurial skills.

\section{Integration of Entrepreneurial Resources}

Entrepreneurship education is not the only business of colleges and universities. Instead a large quantity of entrepreneurial resources outside colleges and universities are neglected by entrepreneurship education in colleges and universities. At present, some of the external resources can be from the government. The government directly or indirectly affect the entrepreneurial practice through various business support subsidies and this part of the external resources can provide substantial help for the entrepreneurship practice, such as business subsidies, tax reduction and exemption and so on; Also, various maker space supported by government are involved. They provide entrepreneurship education all kinds of help, for example, they provide business managers as a business mentor, provide a variety of roadshow opportunities and even docking venture. In addition, some of the external resources can be from society. The first is the public entrepreneurs resource, including the corresponding knowledge unit, such as a variety of WeChat official accounts. The second is the offering of social capital. Beside venture investment, one of the important resources for entrepreneurship capital sources is fundraising. The third is the various practice opportunities. This can provide students visual and straightforward help to understand the operation of enterprises. However, at present all kinds of resources are not well coordinated, so in practice they cannot be effectively transmitted to students to help them understand entrepreneurship and practice entrepreneurship.

\section{PRACTICE-ORIENTED ENTREPRENEURSHIP EDUCATION}

\section{A. The Necessity of Integration of Entrepreneurship Education Resources}

From the above analysis, we can see that the lack of targeting exists in the resources of entrepreneurship education and the supply of educational resources does not match the demand for entrepreneurial resources, which caused entrepreneurship education resources to be inefficient or ineffective. The on-campus resources have their advantages over general teaching, but have limitations on the education in practice. While social resources are more safe and reliable in practice, but in general students don't have easy access to use them. From the students' perspective, different motivations for entrepreneurship education require different resources of entrepreneurship education. Just so, for those students who want to participate in the competition and practice, there is a lack of targeted entrepreneurship education resources. Therefore, it is necessary to integrate and utilize all kinds of resources.

\section{B. The Feasibility of Integration of Entrepreneurship Education Resources}

At present, entrepreneurship education resources are mainly from the school and society, but it is possible to break the borderline. First of all, the colleges and universities have the power to breakthrough on-campus education and practice. All kinds of competitions and assessments will promote further attention to the use of various resources to help college students with entrepreneurship training and practice. The National Challenge Cup Business Plan Competition and "Internet+"e-commerce 
competition has received remarkable attention. In addition, the results of entrepreneurship education have gradually become an index to assess the quality of university teaching. Therefore, in order to achieve better results, universities must break through the current dependence on on-campus resources. Second, the external resources have the impulse to enter the colleges and universities; the external resources need the entrepreneurial entity to achieve different goals; All kinds of maker space need the college students entrepreneurial team; All investors are in desire of the college students' entrepreneurial team to carry on their projects to increase their profit opportunities. Therefore, the breakthrough of both sides of the border will bring a win-win success. The only problem here is the lack of communication platform.

\section{C. "Bi-directional” entrepreneurship education model}

Based on the integration of educational resources and the need for students to accept entrepreneurship education, we proposed a "Bi-directional" entrepreneurial education model. This model is the first quadrant of a two-dimensional coordinate system, in which the vertical axis is the in-school years, from lower grade to higher grade; the horizontal axis is the source of resources, from the school internal resources to external social resources. In their freshmen year, it is mainly the general knowledge of innovation and entrepreneurship education, which satisfies the basic requirements of the education department for university innovation and entrepreneurship, with the emphasis on the universality of participation and preparation for the future differentiated education. In their sophomore year, we will mainly make use of various simulation competitions, practice and training resources to provide students opportunities to gain a certain understanding of management, and make preparations for entrepreneurship. The focus here is screening.

In their junior year, we mainly focus on the cultivation of entrepreneurial talent. We will make full use of the National College Students' innovation project to identify and nurture the entrepreneurial talent. There are two types of projects. The first is the national innovation and entrepreneurship practice and training project, which first gives students grants to practice. The second is the national innovation and entrepreneurship competition program, including business plan competition and extracurricular academic competitions. At this stage social resources can be gradually introduced, such as relevant guidance, enterprise judges review, the roadshow in maker space and so on. At this point we can fully consider the thoughts from the academic school and practical school to offer corresponding guidance and training. In their senior year, we can create entrepreneurial conditions for students. First, we should make use of our own maker space in the campus, and second, we should make use of the maker space that is connected with the school. On one hand, schools provide various conveniences for students to start their own businesses; on the other hand, schools can introduce social capital to broaden the channels of financing for college students. A particular point here is, we need make full use of the resources of alumni enterprises. It is worth noting that in the process of practice, we should not differentiate students strictly by their grade. Some students have better talents, so we should allow them to complete up transition or to the right transition. These students usually have more entrepreneurship and entrepreneurial desire. What's more, we should not forget those students who already had some entrepreneurial experience. We should invite them to return to campus to share their entrepreneurial stories with the on-campus students.

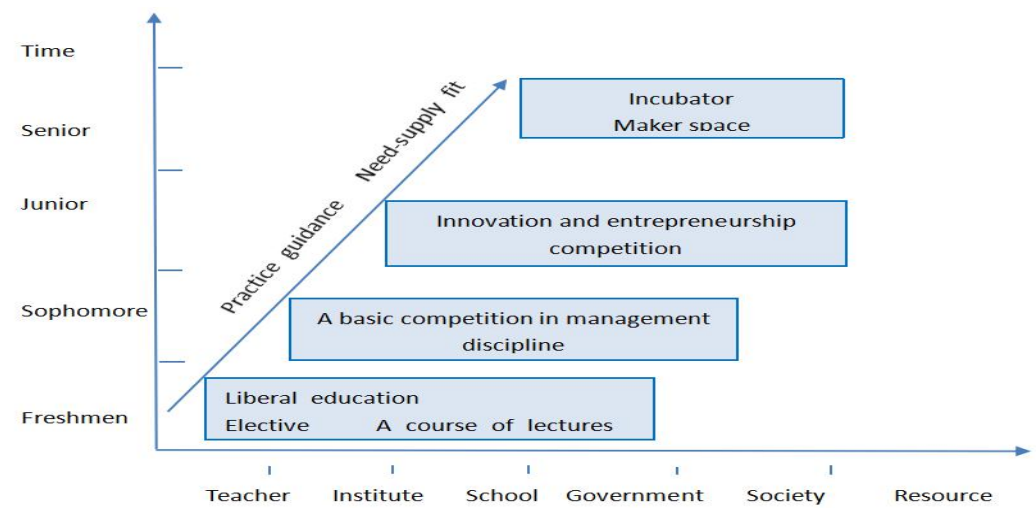

Fig. 1. "Bi-directional" innovation and entrepreneurship education model

\section{The Ecology of Entrepreneurship Education}

The "Bi-directional" entrepreneurship education model should be eventually incorporated into the entrepreneurial environment so that it can maintain a healthy and sustainable development. The premise is, entrepreneurship education should eventually be able to complete docking with maker space to promote its ecological development. According to Guidelines for the Development of Maker space issued by the Ministry of Science and Technology, maker space is a new business service platform that follows a new round of technological revolution and the industrial revolution trends, and effectively meets the mass innovation and entrepreneurship demand in the network era. As an important service carrier for the early business, the maker space provides low- 
cost workspace, network space, social space and resources sharing space for entrepreneurs and form business incubation chain with technology, business incubators, accelerators and industrial parks together. The main function of the maker space is to promote entrepreneurship and development of new technologies, application of new products, development of new markets and cultivation of new formats with professional service, through the combination of innovation and entrepreneurship, the combination of online and offline, and the combination of incubation and investment. As the platform for maker practice, the core practice of the maker space includes courses, workshops and various exchange and competitions and its open resources include open source devices, tools, and methods, aiming to support participatory innovation with flexible space in a cooperative space. The four core elements support each other to form an organic ecosystem.

In order to achieve this ecological system we must do the followings: (1) Cultivating community. This community is a maker group who has the same interests and likes to stay to together to share learning and practice experience and exchange innovative ideas and opinions. (2) Combining online and offline. In recent years, with the rapid development of information technology, new maker space is created. Necessarily, online maker space and traditional maker space should be integrated to fully enjoy the conveniences brought by the information technologies such as mobile Internet, cloud computing, Internet of things and big data. (3) Asking for help from the cross-specialty advisors. The maker space has different sources of makers. Particular attention should be paid to technical boundaries causing difficulties not to be solved effectively. Because of so, the cooperation among advisors from different fields is fairly important. If we make all advisors from different academic backgrounds a cross-specialty advisor team, we will get the necessary support and assistance in professional knowledge, creativity, technology tools, as well as achievement transformation. (4) Making use of the resources of "three creation" or "four innovation" Association to organize corresponding activities, stimulate creativity, innovation, creation, entrepreneurship to achieve wealth. (5) Utilization and regeneration of resources. The resources of maker space should not only be the input type. That is to say, once being weaned it will immediately die. Instead, it should continue to produce new ideas, products or services to survive the market, thus has certain hematopoietic function. (6) Tool support. Makers are the main body of maker space and the practical purpose of entrepreneurship education in Colleges and universities. Providing makers tools that can help them achieve their creative ideas offer direct support to the makers. Our intentions of using the central and local governments to co-build funds to build an entity of bamboo and wood processing factories is just from this source.

\section{SUMMARY}

Practice-oriented entrepreneurship education is the transformation and upgrading of old-fashioned entrepreneurship education model. During the transformation, in order to overcome the difficulties, entrepreneurship education will need the full support of school leaders. Through the top-level design on the training program, entrepreneurship education will reach the goal of gradual stratification and makers screening, and then go through precise training to achieve breakthroughs in their own entrepreneurial talents. In this process, we should also take full consideration into the use of entrepreneurship education resources to form an entrepreneurship education resource network with ecological characteristics so that the makers can fulfill the revolution of creativity without environmental constraints and lay a good foundation for a positive cycle of entrepreneurship education. Thus, "Bi-directional" entrepreneurial education model can avoid empty talk so that entrepreneurship practices will reproduce in the ecological entrepreneurial environment.

\section{ACKNOWLEDGMENT}

This research was financially supported by the Humanities and Social Sciences Research Project of Hubei Province Department of Education (No.16Z027) and the Teaching and research reform project of Wuhan University of Science and Technology (2014z030).

\section{REFERENCES}

[1] Z.Y. Fu, “The Creation Space and Ecological Construction of Pioneering Education,” J. Modern Educational Technology,vol. 5, pp. 18-26, 2015. (In Chinese)

[2] X.M.Yang and J.h. Li, “The Value Potential of the Innovation and the Dispute,” J. Modern Distance Education Research.vol. 2, pp. 23-34, 2015.(In Chinese)

[3] Sheridan K M, Halverson E R, Litts B K, et al,"Learning in the making:A comparative case study of three makerspaces," J. Harvard Educational Review, vol. 4, pp. 505-531, 2014. 